\title{
PLANEJAMENTO TRIBUTÁRIO: ANÁLISE ENTRE O SIMPLES NACIONAL E O LUCRO PRESUMIDO
}

\author{
TAX PLANNING: ANALYSIS BETWEEN NATIONAL SIMPLE \\ AND THE ESTIMATED GAIN
}

Giovana Mattioli Somma ${ }^{1}$

Marlene Kempfer Bassoli ${ }^{2}$

\begin{abstract}
RESUMO: O presente estudo teve início em virtude da necessidade de definição de situações lícitas que, realmente, constituem o planejamento tributário no Brasil. A utilização de método comparativo entre o lucro presumido e o simples nacional a fim de explicitar uma elisão induzida pela lei, principalmente, demonstrar a possibilidade de uma redução da carga tributária e a economia fiscal para as empresas. Sob o enfoque de um Estado de Direito que prestigia os princípios da estrita legalidade e da tipicidade fechada. Em um primeiro momento, o artigo versa sobre o Planejamento Tributário, discorrendo sobre sua conceituação e a idéia de elisão e evasão fiscal. Disserta sobre os princípios constitucionais da legalidade e da estrita legalidade, este sob a ótica da regra-matriz de incidência tributária, a qual determina a hipótese de incidência e a relação jurídica tributária. Considerando a definição legal e o entendimento doutrinário acerca da questão, conceitua o Lucro Presumido e o Simples Nacional. Apresenta na prática um planejamento tributário, analisando a melhor forma de recolhimento do Imposto de Renda e da Contribuição Social sobre o Lucro Líquido, por uma empresa microempresa.
\end{abstract}

Palavras-Chave: Planejamento Tributário; Lucro Presumido; Simples Nacional.

\begin{abstract}
This study was initiated because of the need to define the legal situation that, really, is the tax planning in Brazil. The use of comparative method between the estimated gain and the national simple level to clarify an avoidance induced by the law, mainly, demonstrate the possibility of a reduced tax burden and tax savings for companies. Under the focus of the State of Law that honors the principles of strict legality and typicality closed. At first, the article focuses on Tax Planning, talking about his concept and idea of avoidance and tax evasion. Lectures on the constitutional principles of legality and strict legality, this from the perspective of rule-array of tax incidence, which determines the possibility of incidence and tax relationship. Considering the statutory definition and understanding of doctrine on the issue, conceptualizes the Presumed Gain and the National Simple. It presents a practical tax planning, analyzing how best to collect Income Tax and Social Contribution on Net Income, by a microenterprise.
\end{abstract}

Palavras-Chave: Tax Planning; Presumed Gain; National Simple.

1 Graduanda de Direito pela Universidade Estadual de Londrina, graduanda de Ciências Contábeis pela Pontifícia Universidade Católica - Campus Londrina - PR.

2 Professora da graduação (PUC-PR), especialização e Mestrado em Direito da UEL-PR, UNIMAR-SP 


\section{INTRODUÇÃO}

Diante da necessidade de uma empresa reduzir seus custos, proteger seu patrimônio, resguardar seu direito como contribuinte, possuir informações úteis para a melhor tomada de decisões, imperioso se faz o planejamento tributário. Compreende-se como tal a conduta preventiva e lícita, praticada pelo contribuinte com o intuito da redução da carga tributária, é este o entendimento predominante na doutrina brasileira.

Do ponto de vista do Estado Liberal a economia tributária é respaldada pela Carta Magna. Haja vista, que o planejamento nasce da necessidade da segurança jurídica e fundamenta-se nos princípios constitucionais tributários da legalidade (Art. $5^{\circ}$, II), da estrita legalidade (Art. 150, I) e o da tipicidade. De modo, o Estado só poderá tributar o que está previsto na lei e somente esta poderia proibir o contribuinte a realizar mecanismos de diminuir seu ônus tributário. Outorga, ainda, o princípio individual da propriedade (Art. $5^{\circ}$, XXII) e da vedação do confisco (Art. 150, IV), consectários do Estado Democrático de Direito.

Com este artigo, pretende evidenciar a legalidade do planejamento tributário de modo a formatar uma explanação acerca do Simples Nacional e do Lucro Presumido, com o intuito de propor uma redução tributária adequada à pessoa jurídica. A proposta tem como escopo uma microempresa do ramo comercial, analisando a melhor forma de arrecadação do Imposto de Renda Pessoa Jurídica e da Contribuição Social sobre o lucro líquido.

\section{PLANEJAMENTO TRIBUTÁRIO, ELISÃO E EVASÃO FISCAL}

Viceja indiscutível, pesquisa realizada pelo Sebrae em que o índice de mortalidade das empresas brasileiras que já estão há quatro anos no mercado é de 59,9\%. No mesmo norte, fez um levantamento das possíveis causas dessa mortalidade e obteve com 29,1\% das respostas que essa causa seria a alta carga tributaria brasileira (RIBEIRO, 2004). Para corroborar com isso, toda empresa que esta no mercado busca sempre diminuir suas despesas. Nesta ordem de idéia tanto para não morrer quanto para viver melhor as empresas buscam cada dia mais fazer a economia de tributo, a qual permite melhorar a estratégia de negócios.

O planejamento tributário lato sensu pode ser definido como qualquer ato que busca alternativas lícitas para redução da carga tributária, tanto no âmbito da pessoa física quanto jurídica. É um procedimento preventivo, o qual nasce da análise de um conjunto normativo, a fim 
de viabilizar o negócio jurídico, com tratamento tributário adequado para cada situação singular. Já em seu sentido estrito é tido como sinônimo de elisão fiscal (ZANELLO, 2008, p. 87).

Ainda, o planejamento tributário no Estado liberal é um direito do contribuinte, este não tem o dever de tolerar a maior carga tributária. Ele possui a discricionariedade de escolher a forma jurídica que mais convêm aos seus negócios. No mesmo norte, o contribuinte não está obrigado a optar pela forma jurídica na qual o fisco aufira a maior receita. Tudo isto, obedecendo à lei (HARTZ apud FILHO, 2002, p. 14)..

Neste sentido a lição de Alfredo Augusto Beceker (apud ROLIM, 1998, p. 51):

É aspiração naturalíssima e intimamente ligada à vida econômica, a de se procurar determinado resultado econômico com maior economia, isto é, com a menor despesa (e os tributos incidirão sobre os atos e fatos necessários à obtenção daquele resultado econômico, são parcelas que integrarão a despesa). Ora, todo o indivíduo, desde que não viole regra jurídica, tem indiscutível liberdade de ordenar seus negócios de modo menos oneroso, inclusive tributariamente. Aliás seria absurdo que o contribuinte, encontrando vários caminhos legais (portanto, lícitos) para chegar ao mesmo resultado, fosse escolher justamente aquele meio que determinasse pagamento de tributo mais elevado.

Há uma estreita conexão entre o conceito de elisão fiscal e a idéia mais ampla de planejamento tributário. Aquela pode ser definida como uma forma lícita adotada pelo contribuinte, com o intuito de reduzir o pagamento do tributo, diante das opções apresentadas de lacunas ou imperfeições da lei tributária. Visa, também, retardar ou evitar o pagamento do tributo por meio de condutas omissivas ou comissivas.

Antonio Roberto Sampaio Dória (apud ROCHA, 2002) ensina a divisão da elisão tributária em duas espécies, como segue:

(a) elisão induzida pela lei e (b) elisão resultante de lacunas da leis. Na primeira espécie, o legislador conscientemente, prevalecendo razões extrafiscais, permite ou induz à prática de certas modalidades de negócios benevolamente tributados ou mesmo excluídos do círculo de incidência (reduções, isenções, não-incidência em determinados casos) - (sic!) [...]. Nestes casos de indução legal não há, em regra, necessidade de o indivíduo amoldar os resultados econômicos, que visa, às formas jurídicas mais adequadas do prisma fiscal. Os resultados objetivados são diretamente atingidos, sem alteração de estrutura negocial com que normalmente vêm revestidos, porquanto a lei, de modo ineludível, assim os quer beneficiar (sic!). Destarte, poder-se-ia denominar tal elisão como imprópria. A verdadeira elisão tributária é a que resulta de lacunas da lei $[\ldots]$. 
O autor continua sua explanação, agora sobre a segunda espécie de elisão fiscal e escreve:

\begin{abstract}
O legislador, que não pode ser oniprevidente deixa malhas e fissuras no sistema tributário, inclusive nos próprios casos em que deseja permitir uma elisão para específicos propósitos, por onde escapam à tributação determinados fatos moldados juridicamente pela inesgotável engenhosidade dos contribuintes, ou de seus assessores, da forma mais benéfica fiscalmente, sem, contudo, os desnaturar a ponto de não mais terem, por conveniências da tributação, a eficácia econômica ou a utilidade negocial que incita à sua realização [...] (DÓRIA apud ROCHA, 2002).
\end{abstract}

In casu, são duas faces de uma mesma moeda, de um lado por meios lícitos encontrase a elisão fiscal, de outro a evasão. As duas situações não podem viver harmonicamente pelo contrário se excluem. Deste modo, Carlos Vaz (apud CARVALHO, 2007, p. 284-285) defende que a evasão "é o ato de frustrar a satisfação do tributo devido. Corresponde, portanto, à modalidade dolosa, ilícita, ou seja, à intenção de não pagar um tributo devido”. O que ele diferencia da elisão fiscal, na qual o contribuinte age na legalidade.

Sampaio Dória (apud MAIDA, 2007. p.70-71) classifica a evasão fiscal como omissiva (intencional ou não) e comissiva (sempre intencional). De modo que a evasão omissiva é divida em imprópria “caracterizada pela abstenção à incidência (evitando a ocorrência dos atos tributáveis) ou pela transferência econômica (repercussão tributária)" e por inação. Esta pode ser analisada por duas óticas: "tanto no modo intencional (caso de sonegação, falta ou atraso no recolhimento), como no modo não intencional (ignorância do dever fiscal - desconhecimento sobre a legislação)".

A evasão comissiva é dividida, pelo conceituado doutrinador, em ilícita e lícita ou legítima. Como exemplos daquela a fraude, a simulação e o concluio. Já desta surge a figura da elisão ou da economia fiscal.

\title{
FUNDAMENTOS CONSTITUCIONAS DO DIREITO AO PLANEJAMENTO TRIBU- TÁRIO
}

Os fundamentos constitucionais do planejamento tributário se dividem em duas vertentes de um lado há os princípios da capacidade contributiva, da isonomia e da solidariedade social, do outro se têm os princípios da estrita legalidade, da tipicidade, da segurança jurídica e da certeza do direito (RIBEIRO; BASSOLI, 2007, p. 151). 
Os defensores dos princípios da capacidade contributiva, da isonomia e da solidariedade social encontram fundamentos no Estado Social. Justificam a supressão da elisão fiscal com o intuito de construir uma sociedade justa e solidária, sob o "argumento de que o princípio da isonomia está a exigir de cada contribuinte em idêntica situação de capacidade contributiva uma mesma contribuição (COÊLHO, 2002, p. 283).”

No entanto, esta teoria agride os princípios da estrita legalidade e da regra de que a obrigação tributária só pode decorrer de um fato jurídico tributário. Posição esta adotada por Cristina Zanello entre outros defensores do estado de direito, assim fundamentado:

O princípio da legalidade, indispensável a segurança jurídica e à proteção dos cidadãos contra o arbítrio do Estado, defende que ao Poder Público só é dado fazer aquilo que é previsto em lei. O poder do Estado é limitado pelo princípio da legalidade assegurando o Estado de Direito. Ademais, diante da legalidade estrita, a incidência de tributos só é possível se a operação tributada ocorrer, de acordo com os ditames da lei (ZANELLO, 2008, p. 83).

Os que consideram os ideários do Estado Liberal encontram fundamentos no princípio da legalidade geral, Art. $5^{\circ}, \mathrm{II}, \mathrm{CF} / 88$, do direito individual à propriedade privada, Art. $5^{\circ}, \mathrm{XXII}$, $\mathrm{CF} / 88$, da estrita legalidade, Art. 150, I, CF/88 e do direito ao não confisco, Art. 150, IV, CF/88 (BRASIL, 1988a). De modo que todo cidadão é livre para escolher a forma que lhe acarrete menor ônus fiscal e suas condutas são pautadas na segurança jurídica, fazendo-se imperioso o princípio da estrita legalidade e o da tipicidade, para garantir o direito ao não confisco e direito individual a propriedade privada (CARVALHO, 2007, p. 307).

\section{PLANEJAMENTO TRIBUTÁRIO SUGERIDO: SIMPLES NACIONAL X LUCRO PRESUMIDO}

A despeito do princípio da estrita legalidade, tipicidade e da segurança jurídica torna-se certo o direito ao planejamento tributário. Este é uma ferramenta "jurídico-estratégica" utilizada por muitas empresas com o objetivo de melhores resultados e, como uma fonte de economia de tributos (RABASSI, 2007, p.24).

Em que pese a forma de tributação escolhida por uma empresa, o planejamento bem estruturado, prepará-la-á para investimentos futuros, além de evitar despesas com gastos não 
previstos. O planejamento deve ser feito com antecedência, o contribuinte deve ser muito bem assessorado, por um contador e advogado, exímios conhecedores da legislação, para orientar a atuação dentro da legalidade. Devem conhecer as situações passíveis de crédito tributário, de imunidades, isenções, despesas e provisões que são dedutíveis da receita, aproveitar-se de lacunas na lei, e estudar as alternativas trazidas por esta (OLIVEIRA, 2010, p. 35-36).

O presente artigo traz uma sugestão de um planejamento tributário calcado em uma elisão fiscal induzida pela lei em que o contribuinte, pessoa jurídica, possui a discricionariedade de optar pelo Simples Nacional ou pelo Lucro Presumido, para apuração do Imposto de Renda Pessoa Física (IRPJ) e da Contribuição Social do Lucro Líquido (CSLL). O contribuinte ao optar por uma dessas formas deverá passar o ano-calendário com a opção adotada, segundo o Art. $13, \S 1^{\circ}$ da Lei ${ }^{\circ}$ 9.718/88 para o lucro presumido (BRASIL, 1988b) e o Art. 16, da LC nº 123/2006, para o simples nacional(BRASIL,2006). Esta alternativaémotivo para ocorreto e prévioplanejamento tributário.

A lei complementar 123/2006 instituiu o regime de arrecadação diferenciado, o Simples Nacional.Segundo.EmseuArt. $1^{\circ}$ versaqueesteémododiferenciadoefavorecidooferecidoàsmicroempresas eas empresas de pequeno deporte. Estas são classificadas conforme oArt. $3^{\circ}$, inc.IeII, em:

\footnotetext{
Art. 3o Para os efeitos desta Lei Complementar, consideram-se microempresas ou empresas de pequeno porte a sociedade empresária, a sociedade simples e o empresário a que se refere o art. 966 da Lei no 10.406, de 10 de janeiro de 2002, devidamente registrados no Registro de Empresas Mercantis ou no Registro Civil de Pessoas Jurídicas, conforme o caso, desde que:

I - no caso das microempresas, o empresário, a pessoa jurídica, ou a ela equiparada, aufira, em cada ano-calendário, receita bruta igual ou inferior a R \$240.000,00 (duzentos e quarenta mil reais);

II - no caso das empresas de pequeno porte, o empresário, a pessoa jurídica, ou a ela equiparada, aufira, em cada ano-calendário, receita bruta superior a R\$240.000,00 (duzentos e quarenta mil reais) e igual ou inferior a $\mathrm{R} \$ 2.400 .000,00$ (dois milhões e quatrocentos mil reais).

$\S 1^{\circ}$ Considera-se receita bruta, para fins do disposto no caput deste artigo, o produto da venda de bens e serviços nas operações de conta própria, o preço dos serviços prestados e o resultado nas operações em conta alheia, não incluídas as vendas canceladas e os descontos incondicionais concedidos (BRASIL, 2006).
}

O Simples Nacional, simplificou o modo de arrecadação resumindo oito tributos em um único documento de arrecadação. Este recolhimento unificado alberga impostos e contribuições da União, Estados, Distrito Federal e Municípios: Imposto de Renda da Pessoa Física (IRPJ); Imposto sobre Produtos Industrializados (IPI); Contribuição Social sobre o Lucro Líquido (CSLL); Contribuição para o Financiamento da Seguridade Social (COFINS); Contribui- 
ção para o PIS/Pasep; Contribuição Patronal Previdenciária (CPP); Imposto sobre Operações Relativas à Circulação de Mercadorias e sobre a Prestação de Serviços de Transporte Interestadual e Intermunicipal e de Comunicação (ICMS); Imposto sobre Serviço de Qualquer Natureza (ISS). Vale repisar que esta lista não elimina a incidência de outros tributos, e também existe a possibilidade de um desses tributos mencionados ser arrecadado separadamente segundo o art. 13, da referida Lei (BRASIL, 2006).

A Lei Complementar 123/2006 organizou as atividades econômicas em cinco grupos: a) empresas comerciais (art. 18, anexo I); b) atividade industrial (art. 18, §5 $5^{\circ}$, anexo II); b) prestação de serviços e locação de bens móveis (art. $18, \S 5^{\circ} \mathrm{B}$, anexo III); c) prestação de serviços (art. $18, \S 5^{\circ} \mathrm{C}$, anexo IV); e) prestação de serviços (art.18, $\S 5^{\circ} \mathrm{D}$, anexo V). Cada categoria define faixas de faturamento presumido que servem para identificar a correspondente alíquota e assim calcular o valor a ser pago. E este valor reúne todos os tributos acima referidos.

Ademais, milita em favor do contribuinte uma outra forma de apuração, que é o lucro presumido, apurado trimestralmente, conforme ano-calendário: 31 de março; 30 de junho; 30 de setembro; 31 de dezembro, segundo o Art. $1^{\circ}$, da Lei n 9.430/1996 (BRASIL, 1996).

É utilizada como forma de tributação simplificada para a determinação da base de cálculo do imposto de renda e da CSLL das pessoas jurídicas que não estiverem obrigadas, no ano-calendário à apuração do lucro real. Estas são as seguintes empresas:

\footnotetext{
a)cuja receita total, no ano calendário anterior, seja superior a $\mathrm{R} \$ 48.000,00$, ou proporcional ao número de meses do período, quando inferior a doze meses; b) cujas atividades sejam de instituições financeiras ou equiparadas; c) que tiverem lucros, rendimentos ou ganhos de capital oriundos do exterior; d) que, autorizadas pela legislação tributária, usufruam de benefícios fiscais relativos à isenção ou redução do imposto; e) que no decorrer do ano calendário, tenham efetuado pagamento mensal pelo regime de estimativa, inclusive mediante balanço ou balancete de suspensão ou redução do imposto; f) cuja atividade seja de factoring (TEIXEIRA, 2005, p. 191-192).
}

De modo que, excluídas essas possibilidades, poderá optar pelo lucro presumido a pessoa jurídica que no ano-calendário anterior auferiu uma receita bruta igual ou inferior ao valor de $\mathrm{R} \$ 48.000 .000,00$ (quarenta e oito milhões de reais).

A receita bruta, acima mencionada, será aquela resultante da somatória da receita bruta com vendas ou prestação de serviços, do ganho de capital, e às demais receitas e resultados positivos decorrentes de receitas não compreendidas na atividade (FABRETTI, 2003, p. 226-227). O lucro presumido será determinado segundo o art. 25, da Lei nº 9.430/1996: 
Art. 25. O lucro presumido será o montante determinado pela soma das seguintes parcelas:

I - o valor resultante da aplicação dos percentuais de que trata o art. 15 da Lei $n^{\circ} 9.249$, de 26 de dezembro de 1995, sobre a receita bruta definida pelo art. 31 da Lei $n^{\circ} 8.981$, de 20 de janeiro de 1995, auferida no período de apuração de que trata o art. $1^{\circ}$ desta Lei;

II - os ganhos de capital, os rendimentos e ganhos líquidos auferidos em aplicações financeiras, as demais receitas e os resultados positivos decorrentes de receitas não abrangidas pelo inciso anterior e demais valores determinados nesta Lei, auferidos naquele mesmo período (BRASIL, 1996).

Os percentuais de presunção sobre a receita bruta mencionados no inciso I do artigo acima citado estão prefixados no Art. 15 da Lei no 9.249/95 (BRASIL, 1995) e assim se posicionam: $8 \%$ para atividades em gerais; $1,6 \%$ para a revenda de combustíveis; $16 \%$ para serviços de transporte, com exceção de carga, este é de 8\%; 32\% para serviços em geral, com exceção dos serviços hospitalares que é de $8 \%$; e de $32 \%$ para intermediação de negócios e administração, locação ou cessão de bens e direitos de qualquer natureza, inclusive os bens imóveis (FABRETTI, 2007, p.221). Em se tratando da alíquota a pessoa jurídica pagará o IRPJ à alíquota de $15 \%$.

Quanto a CSLL, possui como base de cálculo a partir de $1^{\circ}$ de setembro de 2003, pelo Art. 22 da Lei 10.684 (BRASIL, 2003a), os seguintes percentuais: 12\% da receita bruta nas atividades comerciais, industriais, serviços hospitalares e transporte e de $32 \%$ da receita bruta na prestação de serviços em geral (exceto a de serviços hospitalares e transporte), intermediação de negócios, administração, locação ou de bens móveis, imóveis e direitos de qualquer natureza, prestação cumulativa e contínua de assessoria creditícia, mercadológica. A alíquota da Contribuição Social é de 9\% (TEIXEIRA, 2005, p. 195).

As empresas submetidas ao lucro presumido terão que apurar a PIS e a COFINS com base na receita bruta, sob a alíquota de $0,65 \%$ e 3\%, respectivamente (Art. $2^{\circ}$, Lei 10.637/2003 (BRASIL, 2002) e Art. 31 da Lei 10.833/2003). (BRASIL, 2003b).

Por todo o exposto, e considerando a legalidade do planejamento tributário, aplicarse-á a teoria à prática. Tratasse de uma microempresa de comércio, sem filiais, a qual auferiu no ano de 2009 uma receita bruta no valor de $\mathrm{R}$ \$32.603,67 (trinta e dois mil, seiscentos e três reais e sessenta e sete centavos), tal receita foi oriunda da venda de mercadorias.

Ao analisar o anexo I da Lei 123/2006 (BRASIL, 2006) Simples Nacional viceja indiscutível que a empresa Alfa Comércio enquadra-se no anexo I, na faixa de até 120.000,00 (cento e vinte mil reais), com alíquota de $4 \%$, como segue: 
Planejamento Tributário: análise entre o simples nacional e o lucro presumido

\begin{tabular}{|c|c|c|c|c|c|c|c|}
\hline $\begin{array}{l}\text { Receita Bruta } \\
\text { em } 12 \text { meses } \\
\text { (em R\$) }\end{array}$ & Alíquota & IRPJ & CSLL & COFINS & PIS/PASEP & СРP & ICMS \\
\hline Até $120.000,00$ & $4,00 \%$ & $0,00 \%$ & $0,00 \%$ & $0,00 \%$ & $0,00 \%$ & $2,75 \%$ & $1,25 \%$ \\
\hline $\begin{array}{l}\text { De } 120.000,01 \text { à } \\
240.000,00\end{array}$ & $5.47 \%$ & $0,00 \%$ & $0,00 \%$ & $0,86 \%$ & $0,00 \%$ & $2,75 \%$ & $1,86 \%$ \\
\hline $\begin{array}{l}\text { De } 240.000,01 \text { à } \\
360.000,00\end{array}$ & $6,84 \%$ & $0,27 \%$ & $0,31 \%$ & $0,95 \%$ & $0,23 \%$ & $2,75 \%$ & $2,33 \%$ \\
\hline $\begin{array}{l}\text { De } 360.000,01 \text { à } \\
480.000,00\end{array}$ & $7,54 \%$ & $0,35 \%$ & $0,35 \%$ & $1,04 \%$ & $0,25 \%$ & $2,99 \%$ & $2,56 \%$ \\
\hline $\begin{array}{l}\text { De } 480.000,01 \\
\text { à } 600.000,00\end{array}$ & $7,60 \%$ & $0,35 \%$ & $0,35 \%$ & $1,05 \%$ & $0,25 \%$ & $3,02 \%$ & $2,58 \%$ \\
\hline $\begin{array}{l}\text { De } 600.000,01 \text { à } \\
720.000,00\end{array}$ & $8,28 \%$ & $0,38 \%$ & $0,38 \%$ & $1,15 \%$ & $0,27 \%$ & $3,28 \%$ & $2,82 \%$ \\
\hline $\begin{array}{l}\text { De } 720.000,01 \text { à } \\
840.000,00\end{array}$ & $8,36 \%$ & $0,39 \%$ & $0,39 \%$ & $1,16 \%$ & $0,28 \%$ & $3,30 \%$ & $2,84 \%$ \\
\hline $\begin{array}{l}\text { De } 840.000,01 \text { à } \\
960.000,00\end{array}$ & $8,45 \%$ & $0,39 \%$ & $0,39 \%$ & $1,17 \%$ & $0,28 \%$ & $3,35 \%$ & $2,87 \%$ \\
\hline $\begin{array}{l}\text { De } 960.000,01 \text { à } \\
1080.000,00\end{array}$ & $9,03 \%$ & $0,42 \%$ & $0,42 \%$ & $1,25 \%$ & $0,30 \%$ & $3,57 \%$ & $3,07 \%$ \\
\hline $\begin{array}{l}\text { De } 1080.000,01 \\
\text { à } 1200.000,00 \\
\end{array}$ & $9,12 \%$ & $0,43 \%$ & $0,43 \%$ & $1,26 \%$ & $0,30 \%$ & $3,60 \%$ & $3,10 \%$ \\
\hline $\begin{array}{l}\text { De } 1200.000,01 \\
\text { à } 1320.000,00\end{array}$ & $9,95 \%$ & $0,46 \%$ & $0,46 \%$ & $1,38 \%$ & $0,33 \%$ & $3,94 \%$ & $3,38 \%$ \\
\hline $\begin{array}{l}\text { De } 1320.000,01 \\
\text { à } 1440.000,00\end{array}$ & $10,04 \%$ & $0,46 \%$ & $0,46 \%$ & $1,39 \%$ & $0,33 \%$ & $3,99 \%$ & $3,41 \%$ \\
\hline $\begin{array}{l}\text { De } 1440.000,01 \\
\text { à } 1560.000,00\end{array}$ & $10,13 \%$ & $0,47 \%$ & $0,47 \%$ & $1,40 \%$ & $0,33 \%$ & $4,01 \%$ & $3,45 \%$ \\
\hline $\begin{array}{l}\text { De } 1560.000,01 \\
\text { à } 1680.000,00\end{array}$ & $10,23 \%$ & $0,47 \%$ & $0,47 \%$ & $1,42 \%$ & $0,34 \%$ & $4,05 \%$ & $3,48 \%$ \\
\hline $\begin{array}{l}\text { De } 1680.000,01 \\
\text { à } 1800.000,00\end{array}$ & $10,32 \%$ & $0,48 \%$ & $0,48 \%$ & $1,43 \%$ & $0,34 \%$ & $4,08 \%$ & $3,51 \%$ \\
\hline $\begin{array}{l}\text { De } 1800.000,01 \\
\text { à } 1920.000,00\end{array}$ & $11,23 \%$ & $0,52 \%$ & $0,52 \%$ & $1,56 \%$ & $0,37 \%$ & $4,44 \%$ & $3,82 \%$ \\
\hline $\begin{array}{l}\text { De } 1920.000,01 \\
\text { à } 2040.000,00\end{array}$ & $11,32 \%$ & $0,52 \%$ & $0,52 \%$ & $1,57 \%$ & $0,37 \%$ & $4,49 \%$ & $3,85 \%$ \\
\hline $\begin{array}{l}\text { De } 2040.000,01 \\
\text { à } 2160.000,00\end{array}$ & $11,42 \%$ & $0,53 \%$ & $0,53 \%$ & $1,58 \%$ & $0,38 \%$ & $4,52 \%$ & $3,88 \%$ \\
\hline $\begin{array}{l}\text { De 2160.000,01 } \\
\text { à 2280.000,00 }\end{array}$ & $11,51 \%$ & $0,53 \%$ & $0,53 \%$ & $1,60 \%$ & $0,38 \%$ & $4,56 \%$ & $3,91 \%$ \\
\hline $\begin{array}{l}\text { De } 2280.000,01 \\
\text { à } 2400.000,00\end{array}$ & $11,61 \%$ & $0,54 \%$ & $0,54 \%$ & $1,60 \%$ & $0,38 \%$ & $4,60 \%$ & $3,95 \%$ \\
\hline
\end{tabular}

Quadro 1 - Partilha do Simples Nacional - Comércio

Fonte: Lei 123/2006 
Vale ressaltar que pelo decreto do Estado do Paraná, n. ${ }^{\text {o: }} 1.190$ de 2007, em seu Art. $1^{\circ}$, as empresas enquadradas no simples nacional e que aufiram como receita bruta anual a quantia de até R \$ 360.000,00 (trezentos e sessenta mil reais) estão isentas do ICMS.

A empresa Alfa Comércio pagará sobre sua receita bruta a alíquota de 2,75\% (4\% tabela do simples menos $1,25 \%$ da isenção do ICMS). De modo que ao aplicar esta alíquota na receita bruta, resulta um montante de $\mathrm{R} \$ 896,60$ (oitocentos e noventa e seis reais e sessenta centavos) a serem pagos ao Estado, apurado pelo Simples Nacional.

Pela analise comparativa em questão utilizar-se-á o Lucro Presumido sobre a mesma receita bruta de $\mathrm{R} \$ 32.603,67$ (trinta e dois mil seiscentos e três reais e sessenta e sete centavos). Aplicando-se o percentual de presunção de $8 \%$ sobre esta receita proveniente das vendas de mercadorias resulta na base de cálculo para o Imposto de Renda de R \$ 2.608,29 (dois mil, seiscentos e oito reais e vinte e nove centavos). A alíquota do IR é de $15 \%$ e o imposto de renda a ser pago no valor de $\mathrm{R} \$ 391,24$ (trezentos e noventa e um reais e vinte e quatro centavos).

Para fim de cálculo da CSLL, sobre a mesma receita bruta retirasse um percentual de $12 \%$, por ser uma empresa comercial, derivando uma base de cálculo no valor de $\mathrm{R} \$ 3.912,44$ (três mil, novecentos e doze reais e quarenta e quatro centavos). Desta base de cálculo aplicasse a alíquota de 9\%, o valor de R \$352,12 (trezentos e cinqüenta e dois reais e doze centavos) será pago à União a título de Contribuição Social sobre o Lucro Líquido.

Quanto ao PIS e a CONFINS, aplicasse sobre a receita bruta as alíquotas de $0,65 \%$ e $3 \%$ respectivamente, resultando nos valores de $\mathrm{R} \$ 211,92$ (duzentos e onze reais e noventa e dois centavos) e R $\$ 978,11$ (novecentos e setenta e oito reais e onze centavos).

A soma do IRPJ (R $\$ 391,24)$, da CSLL $(\mathrm{R} \$ 352,12)$, da PIS (R\$211,92) e da COFINS (R\$ 978,11) resulta no montante a ser pago ao sujeito ativo desta relação jurídica tributária, totalizando em R $\$ 1.933,39$ (um mil, novecentos e trinta e três reais e trinta e nove centavos).

Ao comparar o Simples Nacional com o Lucro Presumido, na empresa "Alfa Comércio", fica evidente que o Simples Nacional veio para simplificar a forma de tributação e ainda reduzir a carga tributária. De modo que o recolhimento pelo regime do simples nacional será realizado pela quantia de $\mathrm{R} \$ \mathrm{R} \$ 896,60$ (oitocentos e noventa e seis reais e sessenta centavos) e na opção do lucro presumido a quantia de tributo perfaz o valor de $\mathrm{R} \$ 1.933,39$ (um mil, novecentos e trinta e três reais e trinta e nove centavos). Portanto, no caso estudo a empresa "Alfa Comércio" deverá optar pelo método de apuração do simples nacional, de modo que esta opção é vastamente vantajosa em relação ao lucro presumido. 


\section{CONSIDERAÇÕES FINAIS}

Essa pesquisa permite concluir:

1- O direito do contribuinte ao planejamento tributário é necessário, indiscutível e absoluto.

2 - Está pautado em fundamentos constitucionais tributários da legalidade, estrita legalidade, tipicidade, do direito a propriedade e ao não-confisco.

3 - A elisão fiscal, seja disciplinada pela lei ou por lacunas desta, muito embora contrarie a terminologia, é a prática lícita para reduzir o ônus tributário do contribuinte.

4- A evasão fiscal deve ser rechaçada de plano, por constituir-se em forma ilícita de redução ou ausência de pagamento de tributos.

5- $\mathrm{O}$ adequado planejamento tributário, com esteio na legislação de regência, como se buscou demonstrar, se constitui forma jurídica para redução de tributos. A análise comparativa entre o simples nacional e o lucro presumido, está a demonstrar a viabilidade e legalidade deste procedimento.

7 - A discricionariedade da pessoa jurídica em optar legalmente por uma das duas formas de apuração no início de cada ano-calendário, para redução da carga tributária, traz assento concreto quando da análise contábil da empresa Alfa Comércio, citada como exemplo, ao optar pelo Simples Nacional.

8 - Por fim, para que uma empresa e, em especial a micro, objeto do presente estudo, possa ter sobrevida em um mercado altamente concorrencial e competitivo, necessário se faz um planejamento fiscal com adequado tratamento tributário, determinante para o seu êxito ou, em sua falta, para o inevitável insucesso. Como bem demonstrado através da empresa Alfa Comércio, a qual obteve uma economia tributária de $\mathrm{R} \$ 1.036,79$ (um mil e trinta e seis reais e setenta e nove centavos), valor significativo para uma empresa que aufere uma receita bruta anual de R \$ 32.603,67 (trinta e dois mil seiscentos e três reais e sessenta e sete centavos).

\section{REFERENCIAS}

CARVALHO, Ivo César Barreto de. Novas reflexões acerca do planejamento tributário. In: PEIXOTO, Marcelo Magalhães; ANDRADE, José Maria Arruda de (Coord.). Planejamento tributário. São Paulo: MP, 2007. p.283-307.

COÊLHO, Sacha Calmon Navarro. Os limites atuais do planejamento tributário. In: ROCHA, 
Valdir de Oliveira (Coord.). O planejamento tributário e a lei complementar 104. São Paulo: Dialética, 2002. p. 281-319..

FABRETTI, Láudio Camargo. Contabilidade tributária. 8 ed. São Paulo: Atlas. 2003.

. Contabilidade tributária. 10. ed. São Paulo: Atlas, 2007.

FILHO, Aurélio Pitanga Seixas. A interpretação econômica no direito tributário, a lei complementar $n^{\circ}$ 104/2001 e os Limites do Planejamento Tributário. In: ROCHA, Valdir de Oliveira (Coord.). O planejamento tributário e a lei complementar 104. São Paulo: Dialética, 2002. p. 9-19.

MAIDA, Fernando. A importância conceitual da elisão fiscal como instrumento estratégico na prática do planejamento tributário. In: PEIXOTO, Marcelo Magalhães; ANDRADE, José Maria Arruda de (Coord.). Planejamento tributário. São Paulo: MP, 2007. p. 63-89.

OLIVEIRA, Luís Martins de; CHIEREGATO, Renato; PEREZ JUNIOR, José Hernandez; GOMES, Marliete Bezerra. Manual de contabilidade tributária. 8. ed. São Paulo: Atlas, 2010.

RABASSI, Renato Spricido. Reestruturação societária: um estudo alternativo com objetivo de planejamento tributário. Boletim CRC, São Paulo, n.162, p.24-31.

RIBEIRO, Luci. Pesquisa Sebrae revela por que morrem tantas empresas no Brasil.

Disponível em: <http://asn.interjornal.com.br/noticia.kmf?noticia=2185061\&canal=207> . Acesso em: 2 mar. 2010.

RIBEIRO, Maria de Fátima; BASSOLI, Marlene Kempfer. Planejamento tributário e o valor jurídico da solidariedade. In: PEIXOTO, Marcelo Magalhães; ANDRADE, José Maria Arruda de (Coord.). Planejamento tributário. São Paulo: MP, 2007. p.133-153.

ROLIM, João Dácio. Do planejamento tributário como direito o dever do contribuinte: seus contornos jurídicos gerais e específicos. In: ROCHA, V. de Oliveira (Org.). Planejamento fiscal teoria e prática. São Paulo: Dialética, 1998. p.51-67.

TEIXEIRA, Paulo Henrique. Contabilidade como instrumento de economia tributária. 1. ed. Curitiba: Maph, 2005.

ZANELLO, Cristina. Planejamento tributário sob um novo enfoque. Revista Tributária e de Finanças Públicas, v.83, n.16, p.86-97, Nov./ dez., 2008. 